\title{
A narrative review of the antitumor studies of solanine
}

\author{
Shan Luo ${ }^{1}$, Guo-Jiang Tian ${ }^{2}$, Fu-Xiang Yu ${ }^{1}$, Zheng-De Wen ${ }^{1}$ \\ ${ }^{1}$ Department of Surgery, The First Affiliated Hospital of Wenzhou Medical University, Wenzhou, China; ${ }^{2}$ Department of Surgery, Shaoxing People's \\ Hospital, Shaoxing, China \\ Contributions: (I) Conception and design: ZD Wen; (II) Administrative support: FX Yu; (III) Provision of study materials or patients: ZD Wen, GJ \\ Tian; (IV) Collection and assembly of data: S Luo, GJ Tian; (V) Data analysis and interpretation: S Luo, FX Yu; (VI) Manuscript writing: All authors; \\ (VII) Final approval of manuscript: All authors. \\ Correspondence to: Zheng-De Wen; Fu-Xiang Yu. The First Affiliated Hospital of Wenzhou Medical University, Fuxue 2, Wenzhou, China. \\ Email: wenzhengde@126.com; wzmublk@163.com.
}

\begin{abstract}
Cancer is a major worldwide public health problem. With the popularity of medical examinations, the improvement of surgical procedures and the application of antitumor drugs, the mortality rate of cancer has declined in recent years, but the quantity remains extremely high. At the same time, with the emergence of tumor drug resistance, it is particularly urgent to seek new and effective drugs for tumor treatment. Solanine, a type of steroidal alkaloid, is the main extract of Solanum nigrum L. Because of its wide biological activity, it has attracted increasing attention, specifically, towards the empirical study of its antitumor activity. This article summarizes the research progress of the antitumor effect and mechanism of solanine over the past 20 years, to provide a reference for workers in the field of cancer research. Studies from 2000 to 2020 were reviewed from PubMed, Springer Link and the Web of Science using the keywords Solanum nigrum L., solanine, $\alpha$-solanine, $\beta$-solanine, $\gamma$-solanine, tumor, cancer and their combinations. Exclude research articles of extraction mixture. Language is limited to English. Solanine shows antitumor ability against different tumors by targeting different proteins. Although there is a lack of clinical largescale studies, a large number of basic pharmacological and toxicological studies have confirmed that solanine may be a new effective cancer drug or adjuvant therapy. Solanine preparations and solanine derivative preparations have broad economic and scientific research prospects.
\end{abstract}

Keywords: Solanum nigrum L.; solanine; tumor

Submitted Oct 19, 2020. Accepted for publication Jan 22, 2021.

doi: 10.21037/tcr-20-3094

View this article at: http://dx.doi.org/10.21037/tcr-20-3094

\section{Introduction}

Cancer is a major worldwide public health problem. With the popularity of medical examinations, the improvement of surgical procedures and the application of antitumor drugs, the mortality rate of cancer has declined in recent years, but the quantity remains extremely high $(1,2)$. In particular, early diagnosis of some tumors, such as pancreatic cancer, is difficult, and patients often lose the chance of surgery be the time they are diagnosed. At the same time, with the emergence of tumor drug resistance, it is particularly urgent to seek new and effective drugs for tumor treatment.

Solanum nigrum $\mathrm{L}$. is a traditional medicinal plant.
A large number of studies have confirmed that Solanum nigrum extract has significant antitumor activity (3-5). With further purification and analysis, it was found that solanine was one of the most important bioactive components. Solanine is a natural steroidal alkaloid, first discovered in 1820 , and was later found to be ubiquitous in plants, such as potatoes and tomatoes. Solanine is divided into $\alpha$-solanine, $\beta$-solanine, and $\gamma$-solanine, of which the $\alpha$-solanine content is the highest (6). Therefore, an increasing number of scholars have begun to study the treatment of tumors with solanine or its component $\alpha$-solanine $(7,8)$.

This review collects the latest research on the different roles of solanine in the treatment of cancer and suggests 
that solanine is a promising drug candidate that can be used alone or in combination with other drugs as an effective antitumor drug. We present the following article in accordance with the Narrative Review reporting checklist (available at http://dx.doi.org/10.21037/tcr-20-3094).

\section{Methods}

Studies from 2000 to 2020 were reviewed from PubMed, Springer Link and the Web of Science using the keywords Solanum nigrum L., solanine, $\alpha$-solanine, $\beta$-solanine, $\gamma$-solanine, tumor, cancer and their combinations. Exclude research articles of extraction mixture. Language is limited to English.

\section{Discussion}

\section{Anti-cell proliferation}

Due to genetic and epigenetic mutations, a rapid cell proliferation rate has become one of the basic characteristics of cancer. Growing tumors not only promote the production of cachexia, but also exert pressure on local organs. Some studies indicate that $\alpha$-solanine downregulates S100 calcium binding protein $\mathrm{P}(\mathrm{S} 100 \mathrm{P})$ expression in colorectal cancer cells in a dose- and time-dependent manner, while blocking the cell cycle at G0/G1 phase, and inhibiting the expression level of cyclin D1 and CDK2, thereby inhibiting the proliferation of human colorectal cancer cells $(9,10)$. Solanine also inhibits the proliferation of human prostate cancer xenografts in nude mice by significantly inhibiting the mRNA and protein expression of cyclin D1, cyclin E1, cyclin dependent kinase 2 (CDK2), CDK4 and CDK6 in vivo $(11,12)$. A number of studies have confirmed that solanine has strong anti-cell proliferation effects on leukemia $(13,14)$, endometrial cancer (15), liver cancer $(16,17)$, esophageal cancer (18), pancreatic cancer (19) and so on (20).

\section{Induction of apoptosis}

Apoptosis is a type of programmed cell death controlled by gene regulation. Maintaining homeostasis of cell numbers requires a balance between the effects of proliferation and apoptosis. Inducing apoptosis has become a new model for the study of cancer therapy. In-depth study of the regulatory mechanism of drug-induced apoptosis provides new ideas and methods for the development of cancer drugs. One study found that solanine opened the permeability transition channel in the membrane, which led to an increase in $\mathrm{Ca}(2+)$ concentration, thus causing membrane rupture and releasing caspase-activating factors (21). Additionally, solanine induces apoptosis of cells by regulating the ROS and Bax/Bcl-2 pathway $(11,14)$. The combination of multiple studies illustrates that apoptosis is another important mechanism by which solanine exerts its antitumor effects $(22,23)$.

\section{Induction of autophagy}

Autophagy is the self-digestion of cells. What distinguishes autophagy from cell necrosis is that autophagy breaks down organelles and cellular proteins through lysosomes. Under normal conditions, cell autophagy is maintained at a low basal level, but increasing studies have found that inducing autophagy in tumor cells may be an important direction for the development of new antitumor drugs. Experiments such as electron microscopy observation, western blotting detection of autophagy markers, and immunofluorescence detection of microtubule-associated proteins $1 \mathrm{~A} / 1 \mathrm{~B}$ light chain 3B (LC3) found that $\alpha$-solanine increases levels of intracellular oxygen free radicals and induces autophagy through the protein kinase B (AKT)/mammalian target of rapamycin (mTOR) signaling pathway (24). Thus, $\alpha$-solanine can be used as a potential inducer of autophagy.

\section{Restrained migration and invasion}

Tumor recurrence and metastasis are the main causes of death of most cancer patients. The epithelial-mesenchymal transition (EMT) plays an important role and gives cells a greater ability to move and invade. Matrix metallopeptidases (MMPs) are the main proteases involved in tumor cell metastasis, spread and invasion (25). The expression of MMP-2 and MMP-9 decreases in cancer cells treated with $\alpha$-solanine $(26,27)$. While the expression level of E-cadherin is significantly higher (18). $\mathrm{Lv}(19)$ also found that solanine inhibits the migration and invasion of the human pancreatic cancer cell lines PANC-1, SW1990, and MIA PACA-2 in a dose-dependent manner by inhibiting the expression of MMP-2/MMP-9 and reducing E-cadherin loss (23).

\section{Inbibition of angiogenesis}

Angiogenesis plays an important role in the growth and development of tumors. Vascular endothelial growth factor (VEGF) is currently the most effective angiogenic 


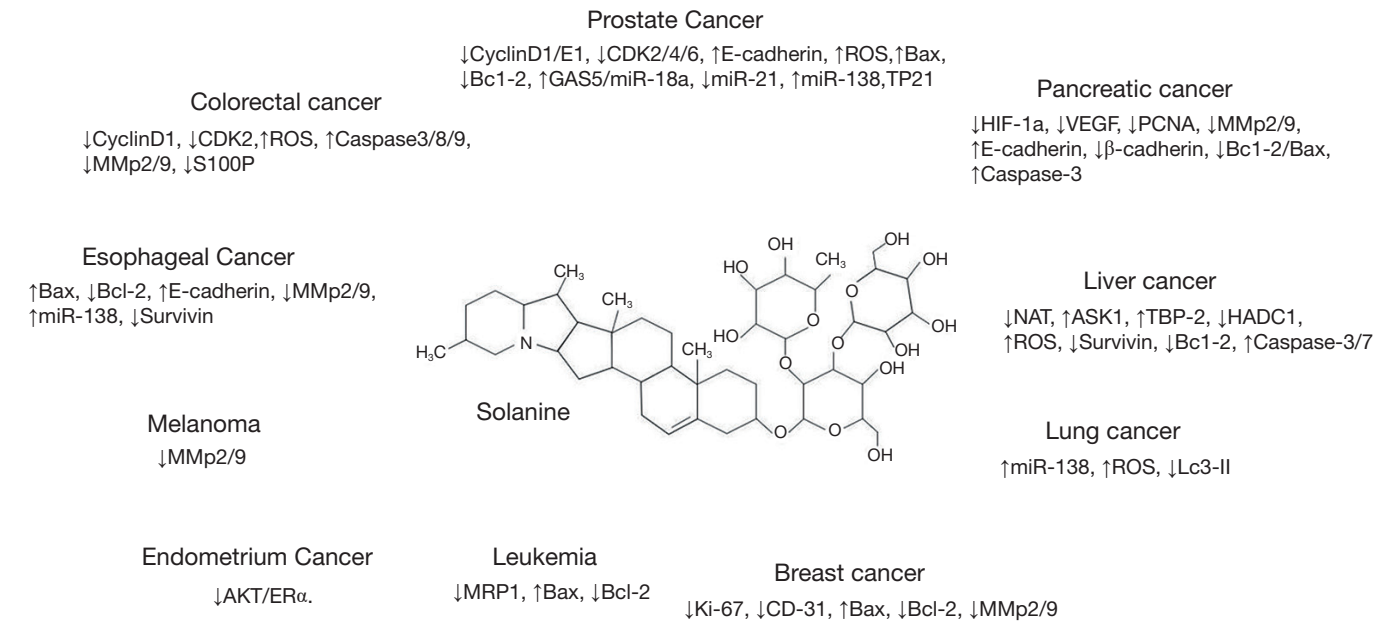

Figure 1 The main proteins targeted by solanine in different cancers. $\downarrow$ Downregulation/inhibition; $\uparrow$ upregulation/activation.

factor. In addition to the effects on angiogenesis and vascular permeability, autocrine VEGF also promotes the dedifferentiation and the EMT of tumors through AKT and extracellular signal-regulated kinase (ERK) 1/2, further enhancing tumor invasion and viability, and plays an important role in the function and self-renewal of tumor stem cells. Several studies have confirmed that $\alpha$-solanine significantly reduces the expression of VEGF in tumors and thus inhibits the survival of blood vessels $(19,28)$. Hypoxia is one of the basic characteristics of tumors (29). $\alpha$-Solanine inhibits VEGF expression by downregulating the ERK1/2hypoxia-inducible factor- $1 \alpha$ and signal transducer and activator of transcription 3 signaling pathways under hypoxic conditions (30).

\section{Improved sensitivity of chemoradiation}

Radiotherapy and chemotherapy are currently the main treatment for patients who cannot surgically remove malignant tumors, and is used in all stages of tumor treatment. The different sensitivity of radiotherapy and chemotherapy leads to different efficacy. $\alpha$-Solanine upregulates the expression of miR-138 in esophageal cancer cells to downregulate survivin expression and enhance the sensitivity of esophageal cancer cells to chemotherapy and radiotherapy $(31,32)$. Zhang et al. demonstrated similar results in lung adenocarcinoma cells (33). At the same time, studies have pointed out that the growth arrest specific 5 (GAS5)/miR-18a axis is another important mechanism promoting the radiosensitivity of prostate cells (12). In the study of leukemia, solanine increases the chemical sensitivity of acute lymphocytic leukemia to doxorubicin, and reverses multidrug resistance in chronic myelogenous leukemia cells by downregulating multidrug resistance protein 1 (MRP1) expression $(13,14)$.

\section{Inbibition of tumor immune escape}

In tumor development and distant metastasis, immune dysfunction is an important influencing factor (34). Tumor immune escape refers to the phenomenon in which tumor cells escape recognition and attack by the body's immune system through a variety of mechanisms, so as to survive and proliferate in the body. It is reported that Solanine may enhance the antitumor immune response by downregulating the proportion of CD4+ CD25+ Treg and the expression of Foxp3 and TGF $\beta$ in tumor tissues (35).

\section{Summary and outlook}

Nowadays, there is a growing concern for discovering drugs from plants which has been playing an increasingly important role in development of anti-tumor drugs. Solanum nigrum is known by the general public as a widely distributed medicinal material. It has advantages of easy acquisition, convenient processing and excellent curative effects; thus, it has good economic development and scientific research value. Solanine shows antitumor ability against different tumors by targeting different proteins (Figure 1). Although there is a lack of clinical large-scale studies on the efficacy of solanine, a large number of basic pharmacological and toxicological studies have confirmed 
that solanine has good antitumor effects. The development of new solanine preparations or their derivative preparations is still one of the key concerns of solanine researchers (36). Indeed, the current research on solanine is in its infancy, and the detailed antitumor mechanism needs to be further explored. In addition, the reported research results need to be verified by other researchers. What is credible is that the development and research of solanine preparations and solanine derivative preparations have broad economic and scientific research prospects.

\section{Acknowledgments}

Funding: The present study was funded by the Wenzhou Municipal Science and Technology Bureau (No. Y20190194).

\section{Footnote}

Reporting Checklist: The authors have completed the Narrative Review reporting checklist. Available at http:// dx.doi.org/10.21037/tcr-20-3094

Conflicts of Interest: All authors have completed the ICMJE uniform disclosure form (available at http://dx.doi. org/10.21037/tcr-20-3094). The authors have no conflicts of interest to declare.

Ethical Statement: The authors are accountable for all aspects of the work in ensuring that questions related to the accuracy or integrity of any part of the work are appropriately investigated and resolved.

Open Access Statement: This is an Open Access article distributed in accordance with the Creative Commons Attribution-NonCommercial-NoDerivs 4.0 International License (CC BY-NC-ND 4.0), which permits the noncommercial replication and distribution of the article with the strict proviso that no changes or edits are made and the original work is properly cited (including links to both the formal publication through the relevant DOI and the license). See: https://creativecommons.org/licenses/by-nc-nd/4.0/.

\section{References}

1. Zheng RS, Sun KX, Zhang SW, et al. Report of cancer epidemiology in China, 2015. Zhonghua Zhong Liu Za Zhi 2019;41:19-28.
2. Siegel RL, Miller KD, Jemal A. Cancer statistics, 2020. CA Cancer J Clin 2020;70:7-30.

3. Kalalinia F, Karimi-Sani I. Anticancer Properties of Solamargine: A Systematic Review. Phytother Res 2017;31:858-70.

4. Lin SR, Chang CH, Hsu CF, et al. Natural compounds as potential adjuvants to cancer therapy: Preclinical evidence. Br J Pharmacol 2020;177:1409-23.

5. Friedman M, Lee KR, Kim HJ, et al. Anticarcinogenic effects of glycoalkaloids from potatoes against human cervical, liver, lymphoma, and stomach cancer cells. J Agric Food Chem 2005;53:6162-9.

6. Friedman M. Chemistry and anticarcinogenic mechanisms of glycoalkaloids produced by eggplants, potatoes, and tomatoes. J Agric Food Chem 2015;63:3323-37.

7. Butt G, Romero MA, Tahir F, et al. Emerging themes of regulation of oncogenic proteins by Solanum nigrum and its bioactive molecules in different cancers. J Cell Biochem 2018;119:9640-4.

8. Ordóñez Vásquez A, Aguirre-Arzola V, De La GarzaRamos M, et al. Toxicity, Teratogenicity and Anti-cancer Activity of $\alpha$-solanine: A Perspective on Anti-cancer Potential. International Journal of Pharmacology 2019.

9. Ni X, Chen J, Lu F, et al. Anti-Cancer Effect of alphaSolanine by Down-Regulating S100P Expression in Colorectal Cancer Cells. Recent Pat Anticancer Drug Discov 2018;13:240-7.

10. Yan X, Li M, Chen L, et al. alphaSolanine inhibits growth and metastatic potential of human colorectal cancer cells Oncol Rep 2020;43:1387-96.

11. Pan B, Zhong $W$, Deng $Z$, et al. Inhibition of prostate cancer growth by solanine requires the suppression of cell cycle proteins and the activation of ROS/P38 signaling pathway. Cancer Med 2016;5:3214-22.

12. Yang J, Hao T, Sun J, et al. Long noncoding RNA GAS5 modulates alpha-Solanine-induced radiosensitivity by negatively regulating miR-18a in human prostate cancer cells. Biomed Pharmacother 2019;112:108656.

13. Yi YJ, Jia XH, Zhu C, et al. Solanine reverses multidrug resistance in human myelogenous leukemia K562/ADM cells by downregulating MRP1 expression. Oncol Lett 2018;15:10070-6.

14. Yi YJ, Jia XH, Wang JY, et al. Solanine induced apoptosis and increased chemosensitivity to Adriamycin in T-cell acute lymphoblastic leukemia cells. Oncol Lett 2018;15:7383-8.

15. Karaboga Arslan AK, Yerer MB. Alpha-Chaconine and alpha-Solanine Inhibit RL95-2 Endometrium Cancer Cell 
Proliferation by Reducing Expression of Akt (Ser473) and ERalpha (Ser167). Nutrients 2018;10:672.

16. Meng XQ, Zhang W, Zhang F, et al. Solanine-induced reactive oxygen species inhibit the growth of human hepatocellular carcinoma HepG2 cells. Oncol Lett 2016;11:2145-51.

17. Gao S, Tan H, Lang L, et al. The effect of alphasolanine on the activity, gene expression, and kinetics of arylamine $\mathrm{N}$-acetyltransferase in HepG2 cells. Oncol Rep 2018;39:2427-35.

18. Wang L, Sun QQ, Zhang SJ, et al. Inhibitory effect of alpha-solanine on esophageal carcinoma in vitro. Exp Ther Med 2016;12:1525-30.

19. Lv C, Kong H, Dong G, et al. Antitumor efficacy of $\alpha$-solanine against pancreatic cancer in vitro and in vivo. PLoS One 2014;9:e87868.

20. Yamashoji S, Matsuda T. Synergistic cytotoxicity induced by $\alpha$-solanine and $\alpha$-chaconine. Food Chem 2013;141:669-74.

21. Gao SY, Wang QJ, Ji YB. Effect of solanine on the membrane potential of mitochondria in HepG2 cells and [Ca2+]i in the cells. World J Gastroenterol 2006;12:3359-67.

22. Ji YB, Gao SY, Ji CF, et al. Induction of apoptosis in HepG2 cells by solanine and Bcl-2 protein. J Ethnopharmacol 2008;115:194-202.

23. Sun $\mathrm{H}, \mathrm{Lv} \mathrm{C}$, Yang $\mathrm{L}$, et al. Solanine induces mitochondria-mediated apoptosis in human pancreatic cancer cells. Biomed Res Int 2014;2014:805926.

24. Hasanain M, Bhattacharjee A, Pandey P, et al. alphaSolanine induces ROS-mediated autophagy through activation of endoplasmic reticulum stress and inhibition of Akt/mTOR pathway. Cell Death Dis 2015;6:e1860.

25. Itoh Y, Nagase H. Matrix metalloproteinases in cancer. Essays Biochem 2002;38:21-36.

26. Lu MK, Shih YW, Chang Chien TT, et al. alpha-Solanine inhibits human melanoma cell migration and invasion

Cite this article as: Luo S, Tian GJ, Yu FX, Wen ZD. A narrative review of the antitumor studies of solanine. Transl Cancer Res 2021;10(3):1578-1582. doi: 10.21037/tcr-20-3094 by reducing matrix metalloproteinase-2/9 activities. Biol Pharm Bull 2010;33:1685-91.

27. Shen KH, Liao AC, Hung JH, et al. alpha-Solanine inhibits invasion of human prostate cancer cell by suppressing epithelial-mesenchymal transition and MMPs expression. Molecules 2014;19:11896-914.

28. Mohsenikia M, Alizadeh AM, Khodayari S, et al. The protective and therapeutic effects of alpha-solanine on mice breast cancer. Eur J Pharmacol 2013;718:1-9.

29. Gilkes DM, Semenza GL, Wirtz D. Hypoxia and the extracellular matrix: drivers of tumour metastasis. Nat Rev Cancer 2014;14:430-9.

30. Wen Z, Huang C, Xu Y, et al. $\alpha$-Solanine inhibits vascular endothelial growth factor expression by down-regulating the ERK1/2-HIF-1 $\alpha$ and STAT3 signaling pathways. Eur J Pharmacol 2016;771:93-8.

31. Wang Y, Wu J, Guo W, et al. alpha-Solanine Modulates the Radiosensitivity of Esophageal Cancer Cells by Inducing MicroRNA 138 Expression. Cell Physiol Biochem 2016;39:996-1010.

32. Wu J, Wang L, Du X, et al. alpha-solanine enhances the chemosensitivity of esophageal cancer cells by inducing microRNA138 expression. Oncol Rep 2018;39:1163-72.

33. Zhang F, Yang R, Zhang G, et al. Anticancer function of alpha-solanine in lung adenocarcinoma cells by inducing microRNA-138 expression. Tumour Biol 2016;37:6437-46.

34. Schaller J, Agudo J. Metastatic Colonization: Escaping Immune Surveillance. Cancers (Basel) 2020;12:3385.

35. Gao J, Ying Y, Wang J, et al. Solanine Inhibits Immune Escape Mediated by Hepatoma Treg Cells via the TGF $\beta /$ Smad Signaling Pathway. Biomed Res Int 2020;2020:9749631.

36. Mohsenikia M, Farhangi B, Alizadeh AM, et al. Therapeutic effects of dendrosomal solanine on a metastatic breast tumor. Life Sci 2016;148:260-7. 